\title{
TRATAMENTO DE EFLUENTES DE CURTUME A PARTIR DA ADSORÇÃO EM QUITOSANA SUBMETIDA A TRATAMENTO COM LÍQUIDO IÔNICO
}

\author{
A. A. MORANDIM-GIANNETTI ${ }^{1}$, K. P. ELIODORIO ${ }^{1}$, V. S. ANDOLFATTO ${ }^{1}$, \\ M. R. G. MARTINS ${ }^{1}$, B. P. DE SÁ ${ }^{1}$, E. R. UMEKI ${ }^{1}$ \\ ${ }^{1}$ Centro Universitário FEI, Departamento de Engenharia Química \\ *E-mail: preamorandim@fei.edu.br
}

\begin{abstract}
RESUMO: Inicialmente, foi realizada a síntese e caracterização do LI acetato de secbutilamônio e ativação da quitosana com o mesmo. Posteriormente, foram realizadas as adsorções de cromo VI, principal íon metálico presente em efluentes de curtume, utilizandose a quitosana ativada, sendo determinados a influência do tempo de estocagem do adsorvente, da quantidade de adsorvente utilizado, do tempo de ensaio, do pH e da temperatura ideais. $O$ tempo de estocagem indicou baixa influência no tratamento e na qualidade do adsorvente, porém, a secagem após o processo de impregnação conferiu ao material maior capacidade de adsorção. $O$ tempo de adsorção foi de 1 hora, a quantidade ideal de $1,00 \mathrm{~g}$ e a temperatura de $25^{\circ} \mathrm{C}$. Com relação ao $\mathrm{pH}$, não foram verificadas alterações significantes na quantidade adsorvida entre 2 a 4,5. Essas condições previamente determinadas foram utilizadas para a realização do tratamento do efluente de curtume, sendo verificada a eficiência da redução do teor do mesmo.
\end{abstract}

PALAVRAS-CHAVE: efluente de curtume; cromo hexavalente; líquido iônico; quitosana ativada

\section{INTRODUÇÃ̃O}

O Cromo é considerado um elemento bioativo essencial, ainda que não se conheça com exatidão suas funções. Por exemplo, sabe-se que o cromo, no corpo humano, possui uma relação com a insulina e o metabolismo de glicose, e é utilizado para prescrição de dietas de emagrecimento. A carência deste metal, bem como seu excesso, pode causar diversos distúrbios, dentre eles, problemas renais (excesso) e problemas de crescimento (ausência).

Porém, o excesso de cromo no meio ambiente traz, principalmente, impactos sobre espécies aquáticas, desde algas até organismos superiores por difusão passiva sendo que, os efeitos da bioacumulação a longo prazo nem sempre são previsíveis, principalmente no caso de compostos como o cromo, que não se decompõem ou que apresentam baixa degradabilidade, acumulando-se no meio ambiente e na cadeia alimentar, onde são absorvidos no organismo em concentrações muito maiores do que as de seu lançamento inicial (FREITAS; 2006). 
A presença do cromo nos corpos hídricos causa impactos, altamente desfavoráveis, afetando a saúde da população humana que consome a água e se alimenta de peixes que se desenvolvem nestes locais. A bioacumulação em humanos pode apresentar efeitos imediatos, efeitos crônicos pela acumulação por longos períodos de tempo e, ainda, consequências genéticas para gerações futuras.

Em termos gerais, o mesmo é muito utilizado no processo de curtição do couro, sendo importante destacar que o couro é uma pele animal que passa por processos de ribeira, curtimento e acabamento para a confecção de calçados, peças de vestuário, revestimentos de mobília e etc. $\mathrm{O}$ curtimento consiste na transformação das peles que, previamente, passam pelo processo de "ribeira", em materiais estáveis e imputrescíveis, ou seja, em couro. Existem processos de curtimento mineral, vegetal e sintético, sendo que, no curtimento mineral, o processo ao cromo é o mais utilizado, devido ao tempo relativamente curto do processo e pela qualidade dada ao couro no fim do processo. Sulfato básico de cromo $\left(\mathrm{Cr}_{2}\left(\mathrm{SO}_{4}\right) \cdot \mathrm{xH}_{2} \mathrm{O}\right)$ é a principal fonte de cromo (FREITAS; 2006).

Durante essa etapa, utilizam-se alguns produtos como o sulfato básico de cromo, tanino de acácia, óxido de magnésio e fungicidas, que levam a produção de um efluente complexo de ser tratado, devido à presença de cromo, o qual possui uma coloração azulada como característica, sendo que, o tratamento deste efluente deve ser realizado com alto controle para o descarte ideal dentro dos limites exigidos pela legislação, pois o cromo é uma agente com alto teor de contaminação. De acordo com a lei $\mathrm{n}^{\circ}$ 997, de 31 de maio de 1976, os limites da CETESB, para qualquer efluente que contenha cromo, são $0,1 \mathrm{mg} / 1$ para cromo hexavalente e $5 \mathrm{mg} / \mathrm{l}$ para cromo total. (PACHECO, 2005)

Neste contexto, o Brasil, que ocupa lugar de destaque na produção de couro mundial, sendo o $5^{\circ}$ maior produtor, representando $11,2 \%$ na produção mundial, atrás de Estados Unidos, Rússia, Índia e Argentina apresenta fortes necessidades de realização de pesquisas de tratamentos de efluentes ricos em cromo sendo que, a região Sul do Brasil, que possui a maior produção de couro bovino com $38 \%$ da produção total se mostra a região mais propícia a apresentar problemas ambientais (PACHECO; 2005).

No Estado de São Paulo, os maiores problemas ambientais apresentados pelos curtumes são os resíduos curtidos e lodos de estações de tratamento que podem conter teores significativos do cromo e outros poluentes, podendo contaminar o solo, as águas superficiais e subterrâneas, ocasionando fortes impactos ambientais tanto para os ecossistemas ao redor como para o ser humano (PACHECO; 2005).

A remoção completa de cromo, ou sua redução até os níveis permitidos pela legislação ambiental exigem investimentos em equipamentos, controle operacional e manutenção, o que torna dispendioso o tratamento dos resíduos do curtume. Vale a pena apontar que no estado do Mato Grosso do Sul, o qual possui o maior rebanho bovino do país (cerca de 25 milhões de cabeças de gado) e possui mais de 11 curtumes, ainda não existe nenhum estudo a respeito dos impactos das emissões do cromo em cursos d'água, desta forma, há a necessidade de avaliar as concentrações de cromo neste tipo de indústria, suas emissões e os impactos causados por esse poluente (FREITAS; 2006).

Nesse contexto, é evidente que pesquisas e desenvolvimento de técnicas eficientes e de 
baixo custo de tratamento de águas e efluentes devem ser realizadas, visando auxiliar na implementação de sistemas de tratamento de efluentes em muitas empresas que, devido ao custo e à fraca fiscalização, muitas vezes não possuem ou não realizam qualquer tipo de tratamento sobre seus efluentes.

Isso não ocorria há algumas décadas atrás, em que não se verificava uma preocupação de se caracterizar a geração de efluentes líquidos industriais nem a de se analisar seus possíveis impactos no meio ambiente. Porém, atualmente, uma nova legislação unida à uma crescente conscientização ambiental, fizeram e ainda fazem com que algumas indústrias desenvolvam atividades para quantificar a vazão e determinar a composição dos efluentes industriais, descritos, segundo a Norma Brasileira - NBR 9800/1987, como o despejo líquido proveniente do estabelecimento industrial, compreendendo emanações de processo industrial, águas de refrigeração poluídas, águas pluviais poluídas e esgoto doméstico.

Assim, visando o cumprimento dessas novas normas, os processos de tratamento de efluentes utilizados podem ser classificados de acordo com a sua natureza química, física e biológica, destacando-se, no caso do cromo, os processos químicos, biológicos e físicos, mais utilizados atualmente.

No processo químico as propriedades químicas dos contaminantes e reagentes caracterizam o tratamento a ser escolhido sendo possível a utilização da coagulação, precipitação, troca iônica, oxidação, neutralização, osmose reversa e ultrafiltração. Já, nos processos biológicos, as reações bioquímicas eliminam contaminantes solúveis ou coloidais podendo ser utilizados processos anaeróbicos ou aeróbicos sendo que, dentre os tipos de tratamento destacam-se os lodos ativados, lagoas aeradas, biodiscos (RBC), filtro percolador, valas de oxidação e reatores sequenciais descontínuos (SBR). No último tipo de processo utilizado, o físico, as propriedades físicas do contaminante tais como, tamanho de partícula, peso específico, viscosidade entre outros devem ser levadas em consideração podendo ser destacados o gradeamento, a sedimentação, a filtração, a flotação e a regularização/equalização, entre outras.

Destes, o tratamento físico-químico é a opção mais indicada no caso de indústrias que geram resíduos líquidos tóxicos, inorgânicos ou orgânicos não biodegradáveis, como as de curtume. Contudo, este tipo de tratamento requer um maior investimento levando em consideração a compra de produtos e reagentes químicos para o processo, espaço físico para instalação dos equipamentos necessários para o tratamento e o transporte do efluente até o local de tratamento. (CIMM, 2015)

Porém, não é apenas na indústria de couro que o cromo hexavalente e do cromo trivalente se tornam vilões em termos de tratamento de águas residuais e meio ambiente, o cromo também faz parte de outras atividades como a fabricação de cimento, galvanoplastia, fabricação de lâmpadas, lixo urbano e industrial, preservativos de madeira, fertilizantes, entre outros, sendo necessário o tratamento desses efluentes antes da realização do descarte.

Neste contexto, durante o tratamento de efluentes contendo cromo podem ser empregados alguns métodos, sendo os mais utilizados atualmente, a precipitação química, filtração com membranas ou adsorção. Por exemplo, para efluentes contendo cromo na indústria de galvanoplastia, o tratamento é realizado por redução e precipitação química. A 
redução do cromo hexavalente para cromo trivalente é realizada com agentes redutores tais como sulfato ferroso, bissulfito de sódio, dióxido de enxofre entre outros, em pH inferior a 3. As reações desses agentes com o cromo acontecem rapidamente e o processo se completa em poucos minutos. Posteriormente o pH é ajustado a um valor entre 7 e 8 e, assim, o cromo e outros metais como zinco, cobre, cádmio, ferro e níquel precipitam na forma de hidróxido e carbonatos produzindo lodo. (BRAILE, 1979)

Outra opção é a utilização de adsorventes poliméricos como a quitosana, que vem sendo estudada atualmente no tratamento de efluentes e que, no futuro, pode se mostrar promissora na redução do teor de metais pesados em resíduos industriais. (KUMAR, 2012)

Um exemplo da utilização da mesma se refere a adsorção de corantes presentes em águas residuais, provenientes da indústria alimentícia e da indústria têxtil, já que os mesmos apresentam baixas taxas de fixação e podem causar sérios danos ao meio ambiente e a saúde. Estudos também mostram que a quitosana apresenta elevados percentuais de remoção e afinidade com vários corantes diferentes, além da vantagem da simplicidade de operação e baixo custo e possibilidade de realização de modificações , como as ativações com LI para aumentar ainda mais sua capacidade de adsorção (VIERA et al., 2014).

Esse tratamento tem mostrado inúmeras vantagens devido, principalmente, as características dos líquidos iônicos, que podem ser definidos como sais formados por cátions orgânicos assimétricos relativamente grandes e ânions orgânicos ou inorgânicos relativamente pequenos, que possuem ponto de fusão menor do que $100^{\circ} \mathrm{C}$, a alta polaridade, estabilidade química e térmica, pressão de vapor extremamente baixa e baixa toxidade (LIN, 2013)

Com relação aos processos de adsorção, os mesmos são processos muito utilizados para separar misturas difíceis de fracionar por extração, destilação ou cristalização. Entre suas aplicações estão o tratamento de resíduos industriais, remoção de corantes para recuperação de solventes, filtros e catalisadores de automóveis, tratamento de efluentes, na indústria alimentícia para remoção de cores, sabores e odores indesejáveis, entre outros.

A adsorção é um processo onde uma substância sólida, líquida ou gasosa é seletivamente transferida para a interface de uma fase sólida ou, em outras palavras, uma fase fluida permeia e preenche os poros de uma fase sólida de modo a ocorrer, por interações físicas e/ou químicas, transferência de massa. O soluto, substância adsorvida, presente em um fluido é denominado sorbato/sorvato e, a fase sólida é chamada de sorbente/sorvente. (MCCABE, 1993).

Porém, durante essa transferência do sorvato para o sorvente, existem alguns fatores que devem ser levados em consideração e analisados de forma a conseguir a máxima eficiência do processo. Esses fatores são a área superficial do sólido (sorvente); a porosidade; a distribuição de tamanho dos poros e a temperatura.

Esses fatores devem ser analisados, devido ao fato dos sólidos apresentarem a propriedade de reter moléculas em sua superfície e, essa retenção pode ser intensificada com a utilização de sólidos finamente divididos ou extremamente porosos, uma vez que, o aumento da área superficial de um sólido possibilita maior contato do mesmo com o soluto 
presente em certo fluido.

Outro fato que deve ser levado em consideração é que as forças que atraem o sorvato para a superfície do sorvente podem ter natureza física ou química, sendo que, na fisissorção (adsorção física), o soluto interage com a superfície sólida através de interações de Van der Waals, as quais são interações dipolo-dipolo e forças de polarização com dipolo induzido, de longo alcance, porém fracas. Uma molécula adsorvida por forças físicas, como a interação de Van der Waals, mantém sua característica, ou seja, ela apenas está sendo atraída para a superfície sólida não existindo ligação química. (MCCABE, 1993)

Por outro lado, na quimissorção o soluto é transferido para a superfície do sólido através de ligações químicas, quase sempre ligações covalentes. Aqui, a molécula do soluto pode ser decomposta devido às forças de valência dos átomos da superfície e, por causa da existência de fragmentos moleculares do soluto na superfície do sólido, há uma tendência do soluto ser adsorvido em certas regiões do sólido, essas regiões são chamadas de sítios.

A adsorção envolve um equilíbrio dinâmico entre as moléculas adsorvidas e dessorvidas, contrário de adsorção e, esse equilíbrio varia em função da temperatura. Mediante disso, o equilíbrio é expresso na quantidade de soluto adsorvido por quantidade de sorvente (massas) em função da concentração do soluto na solução à temperatura constante, ou seja, o equilíbrio pode ser expresso através das isotermas de adsorção.

As isotermas explicitam graficamente a relação de equilíbrio sendo que, as curvas mostram a relação da quantidade de soluto adsorvida por quantidade de sorvente, pela concentração do soluto na solução em uma certa temperatura, ou seja, as curvas mostram as características da adsorção fornecendo informações importantes sobre o processo, podendo apresentar diversas formas, sendo que, as isotermas convexas mostram que grandes quantidades podem ser adsorvidas com baixas concentrações de soluto, logo tais isotermas são classificadas como favoráveis. Já as isotermas côncavas, apresentam características opostas às convexas e, a isoterma linear mostra que a quantidade adsorvida é proporcional à concentração do fluido. (MCCABE, 1993)

Com relação aos processos de adsorção utilizando-se quitosana ativada com LI, a termodinâmica da adsorção espontânea, pela quitosana com certos líquidos iônicos, pode ser explicada através de um efeito cooperativo positivo entre hóspede (líquido iônico) e hospedeiro (quitosana). Esse efeito cooperativo positivo pode ser atribuído à interação dos cátions presentes em líquidos iônicos com os grupos hidroxila da quitosana na forma de ligações de hidrogênio intermoleculares. (KUMAR, 2012)

Outro ponto que deve ser levado em consideração é a presença de grupos aminos protonados na quitosana, devido em grande parte ao $\mathrm{pH}$ do meio como visto em Sakti (2015), os quais irão interagir com ânions de alguns sais de metais presentes em efluentes industriais por interações eletrostáticas. As interações da quitosana, líquido iônico e os ânions (provenientes dos sais de metais pesados presentes em efluentes) são interações físicas, não existindo uma ligação química (KUMAR, 2012).

Assim, visando contribuir com os trabalhos que visam aumentar a eficiência do processo de tratamentos de efluentes ricos em cromo como os efluentes de curtume, este 
trabalho mostra os resultados preliminares de adsorção de íons metálicos de um efluente de curtume sendo verificadas as melhores condições de adsorção, principalmente de cromo VI.

\section{MATERIAIS E MÉTODOS}

\subsection{Materiais}

Para a realização da síntese do líquido iônico, ativação da quitosana e ensaios preliminares de adsorção de cromo em soluções e em efluente de curtume foram utilizados reagentes grau analítico: Ácido acético (>=99,8\%), sec-butilamina $(99,0 \%)$, dicromato de potássio (99,0 \%), metanol (99,9\%), Clororfórmio Deuterado com $0.03 \%$ de TMS (99.6\%\%) foram adquiridos da Sigma Aldrich (St. Louis, MO, USA). Quitosana (grau de desacetilação de 86,7 \%, 80 meshes) foi adquirida da Polymar (Fortaleza, CE, Brazil).

\subsection{Métodos}

Síntese e caracterização dos líquidos iônicos: O líquido iônico acetato de secbutilamônio foi obtido a partir da neutralização ácido-base 1:1 (molar) do ácido acético com a sec-butilamina. Assim, a adição do ácido carboxílico foi realizada sob agitação, lentamente, sob a amina controlando-se a temperatura entre 20 e $30^{\circ} \mathrm{C}$ sendo utilizado, para isso, um agitador mecânico modelo 713D Fisatom (São Paulo, SP, BR).Após a obtenção do líquido iônico, o mesmo foi caracterizado via Ressonância Magnética Nuclear de hidrogênio $\left(\mathrm{RMNH}^{1}\right)$ e de carbono $\left(\mathrm{RMNC}^{13}\right)$ em um Espectrômetro de RMN Bruker Avance III 600 HD (Ettlingen, Baden-Württemberg, GER) localizado no Instituto de Química, UNESP, Araraquara utilizando-se como solvente o clorofórmio deuterado com $0,03 \%$ de tetrametilsilano (TMS).

Tratamento da quitosana com o líquido iônico sintetizado: Durante a etapa de tratamento da quitosana com o líquido iônico, foi adicionada a proporção de $1 \mathrm{~g}$ de líquido iônico para $12 \mathrm{~g}$ de quitosana em um erlenmeyer, sendo utilizados metanol para promover a interação entre a cadeia do biopolímero e íon amônio do líquido iônico. A mistura foi introduzida em aparelho de ultrassom (UltraCleaner, model USC 1600 A, UNIQUE; Brasil) por 2 horas (15 minutos de ultrassom/ 5min repouso). Após essa etapa, o conteúdo foi filtrado, lavado, sendo o resíduo, seco em dessecador à vácuo durante tempos diferentes (2 a 16 semanas).

Determinação da quantidade de adsorvente utilizado: Em laboratório, foi preparada uma solução de dicromato de potássio $\left(\mathrm{K}_{2} \mathrm{Cr}_{2} \mathrm{O}_{7}\right) 36,8 \mathrm{ppm}$ adicionando-se o sal em água destilada. A concentração de cromo hexavalente na solução foi analisada via espectroscopia de emissão atômica (plasma induzido) utilizando um espectrômetro de plasma (ICPE-9000 model, Shimadzu, Japão). Após o preparo da solução estoque, a mesma foi colocada em contato com a quitosana pura e tratada com o líquido iônico. Para isso, certa quantidade de cada adsorvente (quitosana e quitosana ativada) foram adicionadas em erlenmeyers e, nos mesmos, foi adicionada a solução de dicromato de potássio. Os erlenmeyers foram colocados em uma incubadora shaker (Inova 43, Eppendorf International; Alemanha) com agitação por 24 horas, utilizando-se uma temperatura de $25^{\circ} \mathrm{C}$ e um pH de 4,0 . Na sequência, o conteúdo foi filtrado e, a solução tratada, caracterizada por espectroscopia de emissão atômica. Foram 
utilizados 1,0 e $2,0 \mathrm{~g}$ de adsorvente.

Estudo da influência do tempo, $\mathrm{pH}$ e temperatura: Para estudo do tempo, várias amostras de solução de cromo com quitosana tratada com sec-butilamônio foram colocadas sob agitação e utilizando-se as mesmas condições de temperatura e $\mathrm{pH}\left(25^{\circ} \mathrm{C}\right.$ e 4,0$)$. Porém, foram retiradas e filtradas em diferentes tempos, no range de 30 minutos a 10 horas. $\mathrm{O} \mathrm{pH}$ foi estudado variando-se o valor de $\mathrm{pH}$ das soluções de dicromato de potássio numa faixa de 2 a 4,5 , sendo mantida a temperatura em $25^{\circ} \mathrm{C}$ e o tempo de $1,0 \mathrm{~h}$. Para a construção das isotermas de de Langmuir e Freundlich foram preparadas diversas soluções com diferentes concentrações (50 ppm até 500 ppm) de cromo hexavalente, as quais foram colocadas em contato com quitosana tratada utilizando-se uma temperatura de $25^{\circ} \mathrm{C}$, pH igual a 4,0 sendo o processo mantido durante $1,0 \mathrm{~h}$.

Tratamento do efluente de curtume: Obteve-se um efluente de curtume e o mesmo foi caracterizado por espectroscopia de emissão por plasma induzido para determinar a composição química, qualitativa e quantitativa do mesmo. O efluente foi filtrado e submetido ao tratamento com quitosana impregnada com LI acetato de sec-butilamônio e, posteriormente, caracterizado novamente por plasma induzido sendo determinados o teor de cromo, potássio, magnésio e cálcio. $\mathrm{O}$ tempo de adsorção foi de $1,0 \mathrm{~h}$, a temperatura de $25^{\circ} \mathrm{C}$ e o $\mathrm{pH}$ igual a 3,6 .

\section{RESULTADOS E DISCUSSÕES}

\subsection{Síntese e caracterização do líquido iônico}

Todos os reagentes utilizados (sec-butilamina e ácido acético) e o líquido iônico obtido (acetato de sec-butilamônio) foram caracterizados via RMN. Através da análise de espectros de $\mathrm{RMNH}^{1}$, observa-se um deslocamento do sinal referente ao grupo amino após a protonação e formação do cátion amônio de 0,92 para $8,30 \mathrm{ppm}$, respectivamente ao se obter o líquido iônico acetato de sec-butilamônio, o que confirma a formação dos mesmos (Figura 1, Tabela 1). A atribuição dos demais sinais auxiliaram na confirmação da formação dos líquidos iônicos desejados sendo a mesma comparada com dados da literatura (Andrade Neto et al., 2016; Silverstein et al., 2007). Cabe salientar que o sinal referente aos hidrogênios ligados ao carbono 5 encontra-se desdobrado em dois, formando um duplo multipleto, devido a diferença de vizinhança dos hidrogênios.
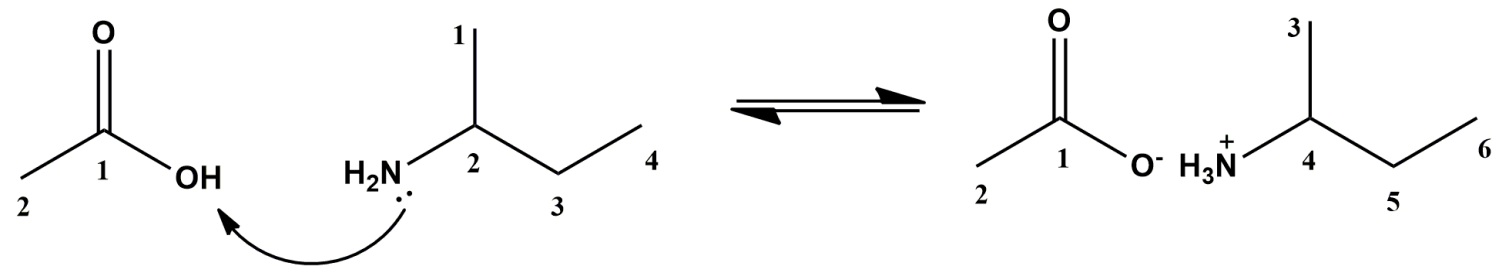

Figura 1 - Reação de formação do LI sintetizado. 
Tabela 1 - Deslocamentos químicos referentes ao $\mathrm{RMN}$ de $\mathrm{H}^{1}$ e de $\mathrm{C}^{13}$

\begin{tabular}{ccc}
\hline Posição & $\boldsymbol{\delta}$ Hidrogênio $(\mathbf{p p m})$ & $\boldsymbol{\delta}$ Carbono $(\mathbf{p p m})$ \\
\hline $\mathbf{1}$ & - & 178,24 \\
$\mathbf{2}$ & $1,93(\mathrm{~s}, 3 \mathrm{H})$ & 28,46 \\
$\mathbf{3}$ & $1,24(\mathrm{~d}, 3 \mathrm{H})$ & 18,84 \\
$\mathbf{4}$ & $3,04(\mathrm{~m}, 1 \mathrm{H})$ & 48,72 \\
$\mathbf{5}$ & $1,54 \mathrm{e} 1,70(\mathrm{~m}$ desdobrado, $2 \mathrm{H}))$ & 23,80 \\
$\mathbf{6}$ & $0,92(\mathrm{t}, 3 \mathrm{H})$ & 9,86 \\
$-\mathbf{N H}^{+}$ & $8,30(\mathrm{~s}, 3 \mathrm{H})$ & - \\
\hline
\end{tabular}

sec-butilamina: $\mathrm{RMNH}^{1}(600 \mathrm{MHz}, \mathrm{CDCl} 3): \delta 0,70(3 \mathrm{H}, \mathrm{d}, \mathrm{H}-1), 2,45(1 \mathrm{H}, \mathrm{m}, \mathrm{H}-2), 0,98 \mathrm{e}$ $1,00(2 \mathrm{H}, \mathrm{m}, \mathrm{H}-3), 0,55(3 \mathrm{H}, \mathrm{t}, \mathrm{H}-4), 0,92\left(\mathrm{~s}, 2 \mathrm{H}, \mathrm{NH}_{2}\right) . \mathrm{RMNC}^{13}(150 \mathrm{MHz}, \mathrm{CDCl} 3): \delta$ 22,91 (C-1), 47,97 (C-2), 32,32 (C-3) e 10,00 (C-4).

Ácido acético: $\mathrm{RMNH}^{1}(600 \mathrm{MHz}, \mathrm{CDCl} 3): \delta$ 2,12 (2H, s, H-2). RMNC ${ }^{13}(150 \mathrm{MHz}$, CDCl3): $\delta$ 177,67 (C-1) e 21,23 (C-2).

Acetato de sec-butilamônio: $\mathrm{RMNH}^{1}(600 \mathrm{MHz}, \mathrm{CDCl} 3): \delta 1,93(3 \mathrm{H}, \mathrm{s}, \mathrm{H}-2), 1,24(3 \mathrm{H}, \mathrm{d}$, H-3), $3.04(1 \mathrm{H}, \mathrm{m}, \mathrm{H}-4), 1,54 \mathrm{e} 1,70(2 \mathrm{H}, \mathrm{dm}, \mathrm{H}-5), 0,92(3 \mathrm{H}, \mathrm{t}, \mathrm{H}-6), 8.30\left(3 \mathrm{H}, \mathrm{s}, \mathrm{NH}_{3}{ }^{+}\right)$. $\mathrm{RMNC}^{13}$ (150 MHz, CDCl3): $\delta$ 178,24 (C-1), 28,46 (C-2), 18,84 (C-3), 48,72 (C-4), 23,80 (C-5), 9,86 (C-6).

\subsection{Eficiência de adsorção de cromo hexavalente nos adsorventes}

Inicialmente foi verificada a eficiência de adsorção tanto da quitosana, como da quitosana ativada com o LI acetato de sec-butilamônio. A partir dos dados obtidos verificouse que, houve uma elevada adsorção do cromo presente na solução, mas a adsorção foi mais eficiente na quitosana ativada (Tabela 2). Esse fato pode ser explicado pelas interações entre o líquido iônico e a quitosana que favorecem o processo de adsorção de cromo por atrações eletrostáticas.

Ainda com base nos experimentos de análise da eficiência da adsorção da quitosana impregnada com liquido iônico, foi verificado que, em experimentos utilizando-se quitosanas tratadas e armazenadas por diferentes períodos, não houve grande variação na adsorção (Tabela 3), mostrando que o adsorvente mantém suas características após o armazenamento. Também verificou-se que a secagem do material foi muito importante, uma vez que a utilização do material úmido afetou diretamente a adsorção devido a maior dificuldade de ocorrência das atrações eletrostáticas que favorecem a eliminação do metal (Tabela 4).

Tabela 2 - Resultados da análise por espectrometria do plasma

\begin{tabular}{cccc}
\hline Adsorvente & $\begin{array}{c}\text { Massa de } \\
\text { adsorvente }(\mathrm{g})\end{array}$ & $\begin{array}{c}\text { Volume da solução de } \\
\text { dicromato de potássio }(\mathbf{m L})\end{array}$ & $\begin{array}{c}\text { Porcentagem de cromo } \\
\text { total adsorvido }(\%)\end{array}$ \\
\hline Quitosana & $1 \mathrm{~g}$ & 25 & 13,16 \\
Quitosana & $2 \mathrm{~g}$ & 25 & 19,52 \\
Sec-Butil (metanol) & $1 \mathrm{~g}$ & 25 & 97,96 \\
Sec-Butil (metanol) & $2 \mathrm{~g}$ & 25 & 97,94 \\
\hline
\end{tabular}


Tabela 3 - Porcentagem de cromo adsorvido utilizando amostra tratada em metanol em diferentes períodos

\begin{tabular}{cccc}
\hline $\begin{array}{c}\text { Quitosana/ } \\
\begin{array}{c}\text { Acetato de } \boldsymbol{s e c} \text { - } \\
\text { butilamônio }\end{array}\end{array}$ & $\begin{array}{c}\text { Período de } \\
\text { armazenamento }\end{array}$ & $\begin{array}{c}\text { Cromo residual das } \\
\text { amostras (ppm) }\end{array}$ & \% de adsorção \\
\hline $\mathbf{A}$ & 2 semanas & 0,65 & 98,58 \\
$\mathbf{C}$ & 8 semanas & 0,81 & 98,24 \\
$\mathbf{E}$ & 16 semanas & 0,86 & 98,14 \\
\hline
\end{tabular}

Tabela 4 - Influência da secagem nas amostras de quitosana ativadas com o LI

\begin{tabular}{ccc}
\hline $\begin{array}{c}\text { Quitosana/ acetato de } \\
\text { sec-butil amônio }\end{array}$ & $\begin{array}{c}\text { Cromo total residual das } \\
\text { amostras (ppm) }\end{array}$ & \% de adsorção \\
\hline Úmido & 2,12 & 95,37 \\
Seco & 0,86 & 98,14 \\
\hline
\end{tabular}

Os resultados indicaram aumento na capacidade de adsorção para amostras em um período de 15 dias, suficiente para a evaporação completa do solvente. Acredita-se que a polaridade do solvente tenha influência direta nos sítios ativos formados após a impregnação do LI na quitosana, fazendo com que menor quantidade de cromo seja adsorvida neste sólido. Portanto, a secagem foi um fator importante na qualidade de adsorvente, influenciando diretamente na quantidade total adsorvida.

\subsection{Determinação do tempo ótimo}

Nos ensaios para determinação do tempo ótimo de adsorção, ou seja, o tempo necessário para que a quitosana impregnada com líquido iônico atingisse a concentração do equilíbrio, concentração na qual o adsorvente está saturado do metal adsorvido e, então, o conjunto atinja um estado em que os fenômenos de adsorção e dessorção se equilibrem e mantenham velocidades iguais. Foi verificado que, a partir de 1 hora, as quantidades de cromo adsorvido não variação significativa e, portanto, determinou-se que em 1 hora a saturação do adsorvente foi atingida (Figura 2)

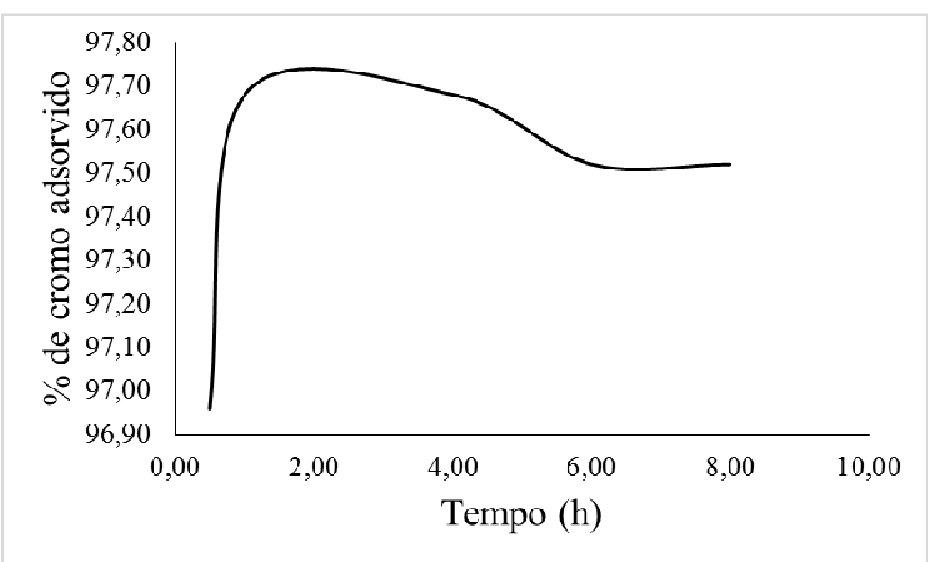

Figura 2 - Porcentagem de cromo adsorvido pela quitosana tratada com acetato de secbutilamônio versus tempo de ensaio em horas. 


\subsection{Influência do pH.}

Sabe-se também que outros fatores, como o $\mathrm{pH}$, influenciam na intensidade da adsorção, com base no mecanismo proposto. Assim, verificou-se o efeito do $\mathrm{pH}$ na adsorção de cromo presente em soluções de dicromato de potássio utilizando-se a quitosana tratada com o acetato de sec-butilamônio sendo pH modificado entre 2,0 e 4,5. A adsorção do cromo hexavalente está ligada à protonação do grupo amino da quitosana tratada, proporcional ao $\mathrm{pH}$ das soluções e, na faixa estudada, não houve variação significativa da quantidade de cromo adsorvida (Figura 3).

Para valores de pH mais elevados, acredita-se que exista diminuição na quantidade adsorvida que pode ser atribuída a desprotonação do grupo amino, impossibilitando esta interação tripla.

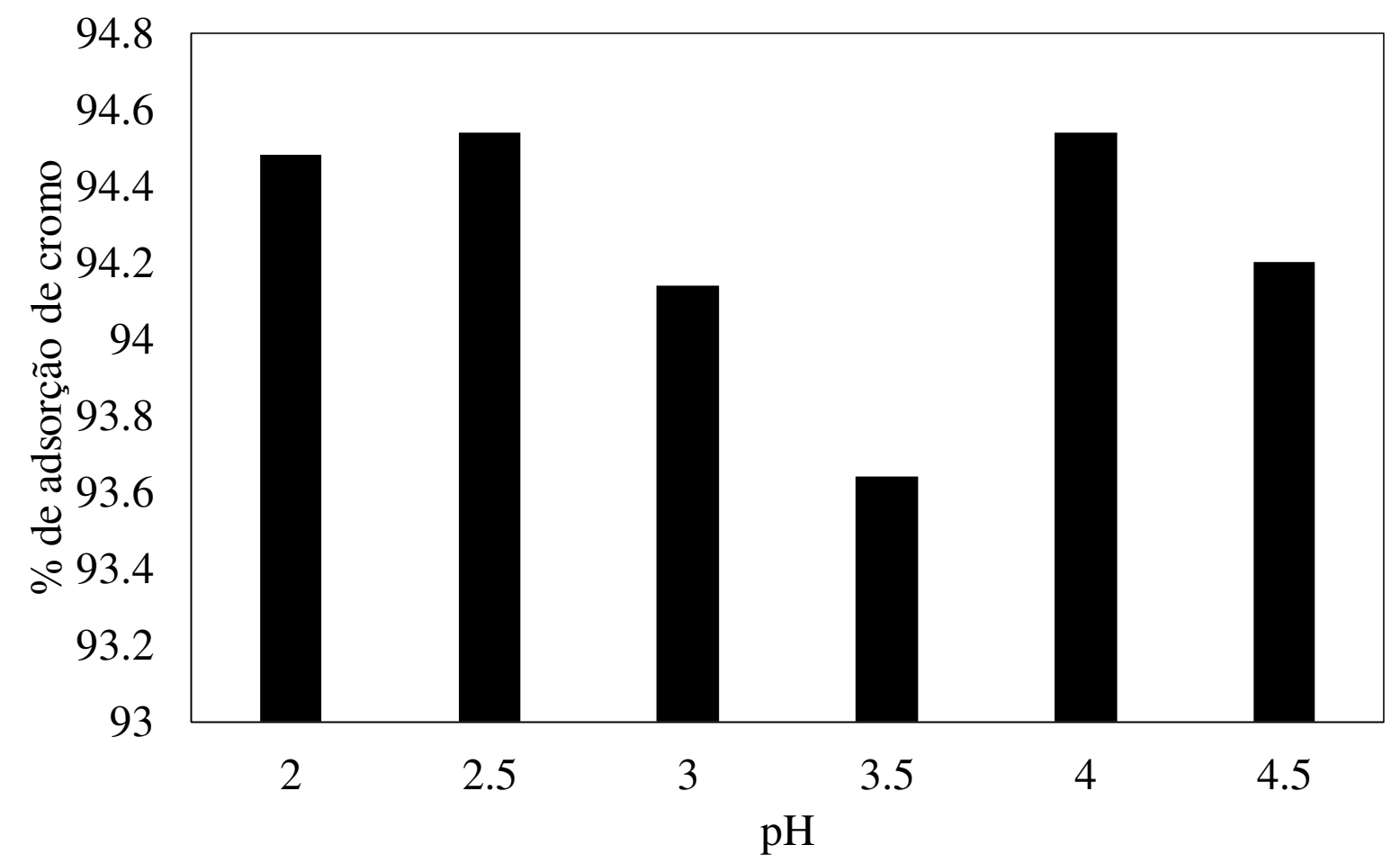

Figura 3: Influência do pH na adsorção de cromo

\subsection{Isoterma de adsorção}

As isotermas de adsorção representam o equilíbrio entre o metal no adsorvente e na fase líquida como função da concentração da solução. Portanto, são de grande importância no estudo de sistema de adsorção. $\mathrm{O}$ fenômeno de adsorção de cromo hexavalente em quitosana tratada com LI acetato de sec-butilamônio foi ajustado a dois modelos: Freundlich e Langmuir. Verificou-se que, para a temperatura de $25 \mathrm{C}$, os parâmetros da isoterma indicaram maior capacidade de adsorção sendo esta, uma temperatura ideal para a aplicação industrial, pois é próxima da temperatura ambiente, acarretando em menor gastos no processo (Figura 4, Tabela 5). 

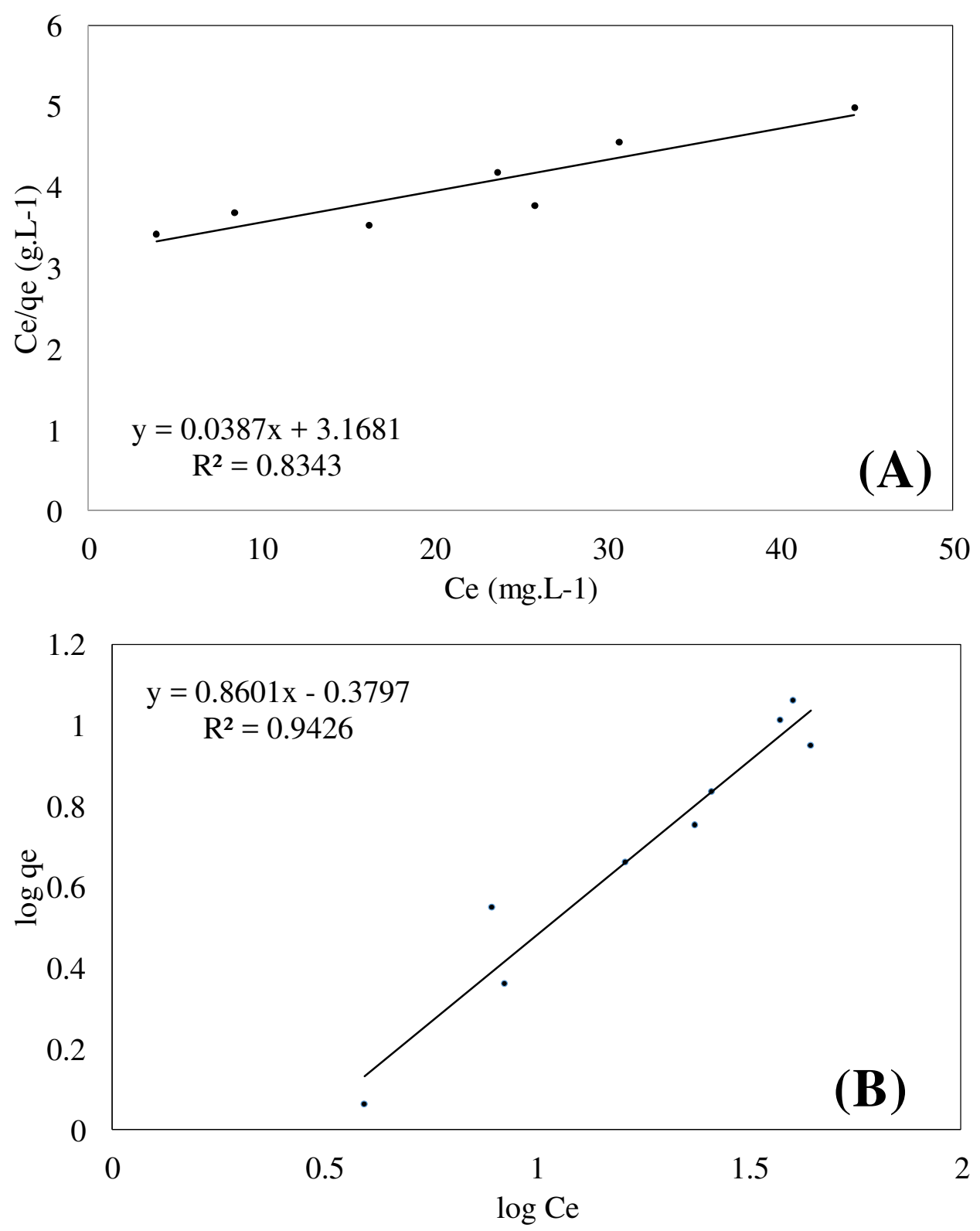

Figura 4: Isoterma de Adsorção: A) de Langmuir a $25{ }^{\circ} \mathrm{C}$ e B) de Freundlich a $25{ }^{\circ} \mathrm{C}$

Tabela 5 - Parâmetros determinados experimentalmente utilizando-se as isotermas de Freundlich e Langmuir a $25^{\circ} \mathrm{C}$

\begin{tabular}{cccc}
\hline Parâmetros & Langmuir & Parâmetros & Freundlich \\
\hline $\mathbf{R L}_{\mathbf{L}}$ & 0,695 & $\mathbf{K f}$ & 0,417 \\
$\mathbf{q o}(\mathbf{m g} / \mathbf{g})$ & 25,840 & $\mathbf{n}$ & 1,163 \\
$\mathbf{b}(\mathbf{L} / \mathbf{m g})$ & 0,012 & & \\
\hline
\end{tabular}

\subsection{Tratamento do efluente industrial de curtume}

Com a determinação das condições ótimas para as soluções de dicromato de potássio, realizou-se o tratamento do efluente industrial de um curtume no interior paulista. Assim, primeiro determinou-se o tempo em que o equilíbrio entre adsorção e dessorção é 
estabelecido e, portanto, o tempo de batelada para este tratamento foi de uma hora. $\mathrm{O} \mathrm{pH}$ foi estudado e não se verificou diferenças significativas na quantidade adsorvida, portanto o tratamento ocorreu no próprio $\mathrm{pH}$ do efluente com valor de 3,6.

Após a verificação das condições de tratamento adequadas, foi realizada uma análise inicial do efluente, que mostrou a presença de cromo e de outros componentes conforme dados expressos na Tabela 6 que indica uma redução na quantidade de cromo após a realização do tratamento de adsorção.

Verifica-se também que outros metais analisados indicaram aumento na concentração, como no caso de magnésio, manganês e ferro. Isto se deve a possíveis erros experimentais na análise ou, ainda por esses metais estarem presentes no par quitosana/ acetato de sec-butil amônio, fazendo com que seu valor final aumentasse.

Tabela 6 - Análise de plasma induzido do efluente antes e depois do tratamento em $\mathrm{mg} / \mathrm{L}$

\begin{tabular}{cccccccccccc}
\hline $\begin{array}{c}\text { Amostra de } \\
\text { efluente }\end{array}$ & \multicolumn{10}{c}{ Elemento químico } \\
\cline { 2 - 13 } & $\mathbf{C a}$ & $\mathbf{F e}$ & $\mathbf{C o}$ & $\mathbf{C r}$ & $\mathbf{K}$ & $\mathbf{M g}$ & $\mathbf{M n}$ & $\mathbf{A l}$ & $\mathbf{B a}$ & $\mathbf{B i}$ & $\mathbf{P}$ \\
\hline sem tratamento & 275 & 0,30 & 0,14 & 874 & 31,90 & 1270 & 0,12 & 2,11 & 1,31 & 2,19 & 13,5 \\
tratado 25 $^{\circ} \mathbf{C}$ & 395 & 0,40 & 0,19 & 772 & 41,50 & 1750 & 0,27 & 1,97 & 1,45 & 1,92 & 13,8 \\
\hline
\end{tabular}

Em relação ao cromo, o mesmo foi adsorvido, porém em quantidades menores do que no estudo com soluções, aproximadamente $12 \%$ da quantidade total foi adsorvido. $\mathrm{O}$ principal fator responsável pela baixa adsorção, como reportado nos estudos de Kumar (2012), são os íons de cobalto, ferro, fósforo e manganês em seus estados oxidativos bivalentes.

Salienta-se também o fato dos íons ferro e manganês serem conhecidos por reduzir o cromo de seu estado hexavalente para o estado trivalente, fazendo com que a eficiência na adsorção diminua. Acredita-se que estes íons concorrem com o cromo pelos sítios ativos formados na quitosana tratada, fazendo com que haja competição e consequentemente, interferindo na efetiva adsorção de cromo.

Outro fator levado em conta no mecanismo é a forma como os íons de cromo hexavalente se encontram no meio. A interação nas soluções ocorria por meio do ânion de cromo conhecido proveniente do dicromato de potássio, enquanto que, para o efluente, não se conhece a forma como os íons de cromo hexavalente se apresentam no meio. Este pode ser um fator determinante para a redução na eficiência de adsorção pelo mecanismo.

Finalmente, mesmo em condições ótimas estudadas a partir de soluções de dicromato de potássio, a adsorção de cromo no efluente não se mostrou eficiente, devido aos diversos íons que interferem no fenômeno e a forma dos íons de cromo no efluente não serem conhecidos. Para as indústrias que buscam alternativas viáveis em um cenário econômico e ambiental, o estudo com quitosana tratada com líquidos iônicos se mostra promissor, sendo necessária, ainda, mais pesquisas sobre operações de adsorção, pois o mesmo se mostra um método efetivo de baixo custo e ambientalmente favorável por reduzir os compostos químicos utilizados no tratamento convencional físico-quimico de alto custo. 


\section{CONCLUSÕES}

Através da análise dos resultados obtidos, verificou-se a eficácia na adsorção utilizando-se a quitosana tratada com líquidos iônicos. Com relação ao tempo e temperatura de tratamento, foi possível a determinação da condição ideal de trabalho bem como o levantamento das isotermas e ajuste do modelo de Langmuir e Freundlich, sendo verificado que a temperatura de $25^{\circ} \mathrm{C}$ é ideal para aplicação.

Dessa forma, o estudo da quitosana tratada com líquidos iônicos mostrou excelentes resultados para a adsorção de cromo, sendo obtidos resultados dentro das normas estabelecidas pela CETESB. Por fim, o trabalho apresenta um método inovador, de baixo custo, ecologicamente favorável, alternativo aos métodos convencionais utilizados atualmente e, a continuação da pesquisa e experimentos, podem ser considerados promissores, visando sempre sua aplicação na indústria e no tratamento em larga escala de cromo nos efluentes líquidos, como os provenientes de curtumes.

\section{AGRADECIMENTOS}

Ao Centro Universitário FEI pelo suporte para o desenvolvimento do trabalho.

\section{REFERÊNCIAS}

Câmara ambiental da indústria de couros, peles, assemelhados e calçados. CETESB, São Paulo, 2005. Disponível em: <http://www.cetesb.sp.gov.br/tecnologiaambiental/cas-em-atividade/44-camara-ambiental-da-industria-de-couros--peles-assemelhados-e-calcados>. Acesso em: 13 mar. 2015.

ANDRADE NETO, J.C.; CABRAL, A.S.; OLIVEIRA, L.R.D.; TORRES, R.B.; MORANDIM-GIANNETTI, A.A. Synthesis and characterization of new low-cost ILs based on butylammonium cation and application to lignocellulose hydrolysis. Carbohydrate Polymers, v.143, p.279-287, 2016.

BNDS. Potencial de diversidade da indústria química Brasileira: Relatório 4 - Químicos para couro. 2014.2 Disponível em: $<$ http://www.bndes.gov.br/SiteBNDES/export/sites/default/bndes_pt/Galerias/Arquivos /produtos/download/aep_fep/chamada_publica_FEPprospec0311_Quimicos_Relat4_Q uimicos_para_couro.pdf $>$. Acesso em: 14 maio 2015.

BRAILE. Pedro Marcio. Companhia de Tecnologia de Saneamento Ambiental. Acabamento de Metais. In: SÃO PAULO. Pedro Marcio Braile. Companhia de Tecnologia de Saneamento Ambiental. Manual de Tratamento de Águas Residuárias Industriais. São Paulo: Cetesb, 1979. Cap. 14. p. 345-353.

CIMM. Efluentes Industriais. Disponível em: $<$ http://www.cimm.com.br/portal/material_didatico/3669-efluentes-industriais\#.Vdx2lNVikq>. Acesso em: 17 jul. 2015.

DE FREITAS, T.C.M.; MELNIKOV, P. O uso e os impactos da reciclagem de cromo em indústrias de curtume em Mato Grosso do Sul, Scientific Electronic Library Online, Rio de Janeiro, oct./dez. 2006. Disponível em: $<$ http://www.scielo.br/scielo.php?script=sci_artartt\&pid=S141341522006000400002>. Acesso em: 12 mar. 2015 
KUMAR, A.S.K.; GUPTA, T.; KAKAN, S.S.; KALIDHASAN, S.; MANASI, RAJESH, V.; RAJESH, N. effective adsorption of hexavalent chromium through a three center (3c) co-operative interaction with an ionic liquid and biopolymer. Journal of Hazardous Materials, p. 213-224. 15 nov. 2012.

LIN, Y.C; YANG, P.M.; CHEN, S.C.; TU Y.T.; LIN, J.F. Biodiesel production asissted by 4-allyl-4-methylmorpholin-4-ium bromine ionic liquid and a microwave heating system. Apllied Thermal Engineering. Kaohsiung, p. 570-576. 04 set. 2013.

MCCABE, W.L.; SMITH, J.C.; HARRIOTT, P. Unit operations of chemical engineering. 5th. ed. c1993. 1130p.

PACHECO, José Wagner Faria. Curtumes. São Paulo: CETESTB, 2005. (Série P+L). Disponível em: <http://www.cetesb.sp.gov.br>. Acesso em: 17 maio 2015.

SILVERSTEIN, R.; WEBSTER, F.; KIEMLE, D. Identificação espectrométrica dos compostos orgânicos. 7. ed. Rio de Janeiro: LTC, 2007.

VIEIRA, M.L.G.; GONÇALVES, J.O.; PIVA, T.; OPPELT, A.P.; VIEIRA, V.A.; PINTO, L.A.A. Aplicação de esferas recobertas com quitosana na adsorção de corante alimentício em coluna de leito fixo. Química e Sociedade: Motores da Sustentabilidade. Rio Grande do Norte, Natal. Nov. 2014. Disponível em: < http://www.abq.org.br/cbq/2014/trabalhos/9/6100-14388.html>. Acesso em: 10 maio 2015.

\title{
TREATMENT OF TANNERY EFFLUENTS FROM ADSORTION IN CHITOSAN SUBMITTED TO IONIC LIQUID TREATMENT
}

\author{
A. A. MORANDIM-GIANNETTII ${ }^{1, *}$ K. P. ELIODORIO ${ }^{1}$, V. S. ANDOLFATTO ${ }^{1}$, \\ M. R. G. MARTINS ${ }^{1}$, B. P. DE SÁ ${ }^{1}$, E. R. UMEKI ${ }^{1}$ \\ ${ }^{1}$ FEI University, Department of Chemical Engineering \\ *E-mail: preamorandim@fei.edu.br
}

\begin{abstract}
Initially, we performed the synthesis and characterization of secbutylammonium acetate IL and chitosan activation with it. Afterwards, we used the activated chitosan to carry out the adsorption of chromium VI, which is the main metallic ion present in tannery effluents. The influence of the adsorbent storage time, adsorbent amount, test time, $\mathrm{pH}$ and temperature were analyzed. The storage time indicated low influence on the treatment and on the quality of the adsorbent; however, drying after the impregnation process gave the material greater adsorption capacity. The adsorption time was 1 hour, the ideal amount of $1.00 \mathrm{~g}$ and the temperature $25^{\circ} \mathrm{C}$. Regarding $\mathrm{pH}$, no significant changes were observed in the amount adsorbed between 2 and 4.5. These previously determined conditions were used for the treatment of the tannery effluent, verifying the efficiency of chromium VI concentration reduction.
\end{abstract}

KEYWORDS: Tannery effluent; Hexavalent chromium; Ionic liquid; Activated chitosan 